\title{
Emergency appendicectomy and meat consumption in the UK
}

\author{
Paul Appleby, Margaret Thorogood, Klim McPherson, Jim Mann
}

\begin{abstract}
Study objective - To compare the rates of reported emergency appendicectomies in a cohort study of vegetarians and nonvegetarians by participants' history of meat consumption

Design-This was a prospective cohort study in which participants were asked about their lifetime history of meat consumption/avoidance and, separately, whether they had had an appendicectomy. Appendicectomy was described as either "emergency" or "non-emergency" according to details supplied by the participant.

Setting - The United Kingdom.

Participants - These comprised more than 11000 people, of whom 4852 (44\%) completed both an appendicectomy form and a dietary questionnaire giving details of their lifetime history of meat consumption.

Main results-The percentage who reported an emergency appendicectomy was higher among lifelong meat eaters $(\mathbf{1 0} \cdot \mathbf{7 \%})$ than either lifelong non-meat eaters $(7 \cdot 8 \%)$ or those who had stopped eating meat $(8 \cdot 0 \%)$; and the operations were performed at an earlier age in this first group (mean values $18 \cdot 9,26 \cdot 0$, and 19.6 years respectively). The overall age adjusted emergency appendicectomy rate ratio comparing participants who did not eat meat with those who ate meat was 0.47 $(95 \%$ confidence interval $0 \cdot 35,0 \cdot 65)$.

Conclusions-The results suggest that people who do not eat meat have a $50 \%$ lower risk of requiring an emergency appendicectomy than those who do. The data do not, however, allow the reliable testing of other hypotheses, so meat consumption may simply be a marker for another dietary, lifestyle, or socioeconomic factor.
\end{abstract}

( $(\mathcal{F}$ Epidemiol Community Health 1995;49:594-596) Health and Policy, London School of

Hygiene and

Tropical Medicine, Keppel Street, London WC1E 7HT $M$ Thorogood

$\mathrm{K}$ McPherson

University of Otago Department of Human Nutrition, PO Box 56,

Dunedin, New Zealand

J Mann

Correspondence to: Mr P Appleby.

Accepted for publication June 1995

Although the incidence of acute appendicitis is declining, appendicectomy remains one of the commonest operations in the UK and other developed countries. ${ }^{1}$ Dietary factors, including the consumption of potatoes, other vegetables, and sugar, have been shown to be associated with acute appendicitis independently of hygiene factors such as the provision of fixed baths and hot water systems. ${ }^{2}$

The Oxford vegetarian study is a nationwide prospective cohort study of 6000 persons who do not eat meat and 5000 persons who do.
This paper describes the incidence of reported emergency appendicectomies in the cohort and compares emergency appendicectomy rates according to the participants' history of meat consumption.

\section{Methods}

Participants in the Oxford vegetarian study were recruited through advertisements, the news media, by word of mouth and, in the case of the meat eaters, as nominated friends and relatives of the vegetarian volunteers, as described elsewhere. ${ }^{3}$ Recruitment to the study took place between September 1980 and January 1984 at which time each participant completed a simple questionnaire covering aspects of health, diet, and other lifestyle factors. During 1985-86, participants were asked to complete a simple form asking whether they had had an appendicectomy and, if so, their age at the time; whether the operation had been performed as an emergency; why the operation had been performed; and whether any other organs were removed at the same time. These details were used to classify each appendicectomy as either "emergency" or "non-emergency". At the same time, participants were asked to complete a separate and much more detailed dietary questionnaire which included a question concerning which periods of their life they had not eaten meat, if any.

Thus, for participants who completed both an appendicectomy form and a dietary questionnaire, were we able to determine the incidence of appendicectomy among three main groups, as follows:

- Lifelong meat eaters (participants who had never excluded meat from their diet);

- Lifelong non-meat eaters (participants who had never included meat in their diet);

- The changeover group (participants who had started life as meat eaters and subsequently given up meat, never having resumed, at least up until the time at which they completed the dietary questionnaire).

The relatively small number of participants 
Table 1 Socioeconomic characteristics of lifelong meat eaters, lifelong non-meat eaters, and participants who became non-meat eaters

\begin{tabular}{|c|c|c|c|}
\hline & Lifelong meat eater & Lifelong non-meat eater & Became non-meat eater \\
\hline $\begin{array}{l}\text { Mean (SD) age (y) } \\
\text { Female } \\
\text { Social class I-II } \\
\text { Social class III-V } \\
\text { Social class other or not known }\end{array}$ & $\begin{array}{ll}46 \cdot 0 & (15 \cdot 4) \\
981 & (59 \cdot 6 \%) \\
867 & (52 \cdot 7 \%) \\
427 & (26 \cdot 0 \%) \\
351 & (21 \cdot 3 \%)\end{array}$ & $\begin{aligned} 47 \cdot 5 & (16 \cdot 9) \\
140 & (63 \cdot 9 \%) \\
122 & (55 \cdot 7 \%) \\
36 & (16 \cdot 4 \%) \\
61 & (27 \cdot 9 \%)\end{aligned}$ & $\begin{aligned} 45 \cdot 6 & (16 \cdot 5) \\
1782 & (69 \cdot 8 \%) \\
1209 & (47 \cdot 4 \%) \\
680 & (26 \cdot 6 \%) \\
664 & (26 \cdot 0 \%)\end{aligned}$ \\
\hline
\end{tabular}

- Lifelong non-meat eaters contribute personyears at risk to the "not eating meat" category only;

- Members of the changeover group contribute person-years at risk to the "eating meat" category up to the time of their change of diet and to the "not eating meat" category thereafter, unless they had an appendicectomy before giving up meat, in which case they contribute person-years at risk to the "eating meat" category only.

Participants in all three diet groups contribute person-years at risk from birth until the time of their appendicectomy (emergency or nonemergency) if they had one or until completion of their appendicectomy form and dietary questionnaire if they did not.

The SPSS ${ }^{4}$ was used for the tabulations and calculations of mean age at the time of the appendicectomy, Person-years ${ }^{5}$ was used to calculate the appendicectomy rates, and $G L I M^{6}$ was used for a Poisson regression analysis of the data. Participants who reported having an appendicectomy were assumed to have had the operation on their birthday. For example, a participant who reported having an appendicectomy when aged 15 was taken to have had the operation on their 15 th birthday.

\section{Results}

Altogether 4852 participants ( $44 \%$ of the study cohort) completed both an appendicectomy form and a dietary questionnaire (67 participants completed an appendicectomy form but either did not complete the dietary questionnaire or did not answer the question concerning which periods of their life they had not eaten meat). Of these, 1645 participants were

Table 2 Number (\%) of appendicectomies among lifelong meat eaters, lifelong non-meat eaters, and participants who became non-meat eaters

\begin{tabular}{llll}
\hline Type of operation & Lifelong meat eater & Lifelong non-meat eater & Became non-meat eater \\
\hline None & $1382(84 \cdot 0)$ & $191(87 \cdot 2)$ & $2201(86 \cdot 2)$ \\
Non-emergency & $87(5 \cdot 3)$ & $11(5 \cdot 0)$ & $149(5 \cdot 8)$ \\
Emergency & $176(10 \cdot 7)$ & $17(7 \cdot 8)$ & $203(8 \cdot 0)$ \\
\hline
\end{tabular}

lifelong meat eaters, 219 participants were lifelong non-meat eaters, and 2553 participants belonged to the changeover group (giving up meat at a mean of 27.5 years; range $1-82$ years). The 435 participants with a more complicated diet history were excluded from the analysis. Socioeconomic characteristics of the 4417 participants included in the analysis are shown in table 1 .

A total of 643 appendicectomies, including 396 emergency operations, were reported among participants included in the analysis. The incidence of appendicectomies in relation to diet group is shown in table 2.

The percentage of reported emergency appendicectomies was greater in the lifeling meat eaters $(10.7 \%)$ than in either the lifelong nonmeat eaters $(7 \cdot 8 \%)$ or the changeover group $(8.0 \%)$ and the operations were performed at an earlier age (mean values $18 \cdot 9,26 \cdot 0$, and $19 \cdot 6$ years respectively). The reported emergency appendicectomy rates were $257 \cdot 6,174 \cdot 4$, and 189.5 per 100000 person-years respectively. The differences were similar for both men $(272.7 v 198.0 v 176.3)$ and women $(246.7 v$ $161.0 v 195 \cdot 6)$.

Reported emergency appendicectomy rates for men and women in each of nine age groups and two diet categories ("eating meat" and "not eating meat") are shown in table 3. The emergency appendicectomy rates peak during teenage years and are generally lower in the "not eating meat" category than in the "eating meat" category for both men and women. The 396 reported emergency appendicectomies were observed in a total of more than 185000 person-years at risk. A Poisson regression analysis showed highly significant $(p<0.001)$ differences in reported emergency appendicectomy rates between diet categories and between age groups but no significant difference between males and females. The overall, age adjusted rate ratio comparing the "not eating meat" category with the "eating meat" category was 0.47 (95\% confidence interval $0.35,0.65$ ), indicating a $50 \%$ lower risk of emergency appendicectomy while avoiding meat. The risk is lower in the "not eating meat"

Table 3 Emergency appendicectomy rate per 100000 person-years (and number of emergency appendicectomies) by gender, age group, and meat eating category and rate ratios (and 95\% confidence intervals) comparing participants who did not eat meat with those who ate meat, in relation to age group

\begin{tabular}{|c|c|c|c|c|c|}
\hline $\begin{array}{l}\text { Age at which reported } \\
\text { appendicectomy occurred (y) }\end{array}$ & $\begin{array}{l}\text { Males } \\
\text { eating meat }\end{array}$ & $\begin{array}{l}\text { Males not } \\
\text { eating meat }\end{array}$ & $\begin{array}{l}\text { Females } \\
\text { eating meat }\end{array}$ & $\begin{array}{l}\text { Females not } \\
\text { eating meat }\end{array}$ & $\begin{array}{l}\text { Rate ratio (not eating meat } \\
\text { versus eating meat) }(95 \% \mathrm{CI})\end{array}$ \\
\hline $\begin{array}{l}0-4 \\
5-9 \\
10-14 \\
15-19 \\
20-24 \\
25-29 \\
30-34 \\
35-39 \\
40+\end{array}$ & $\begin{array}{l}14.0(1) \\
331 \cdot 0(23) \\
541 \cdot 8(36) \\
403.6(25) \\
395 \cdot 2(21) \\
140.4(6) \\
87.7(3) \\
340 \cdot 8(9) \\
100 \cdot 3(7)\end{array}$ & $\begin{array}{r}0 \cdot 0(0) \\
0 \cdot 0(0) \\
343 \cdot 4(2) \\
244 \cdot 3(2) \\
0 \cdot 0(0) \\
186 \cdot 8(4) \\
140 \cdot 7(3) \\
125 \cdot 1(2) \\
14.5(1)\end{array}$ & $\begin{array}{c}50 \cdot 9(7) \\
224.9(30) \\
406 \cdot 7(51) \\
514.2(57) \\
311.5(28) \\
238.7(17) \\
165.0(9) \\
198.8(8) \\
97.5(9)\end{array}$ & $\begin{array}{r}135 \cdot 1(1) \\
0.0(0) \\
67.5(1) \\
197 \cdot 6(5) \\
125 \cdot 8(5) \\
176.6(8) \\
50.2(2) \\
131.6(4) \\
73.8(9)\end{array}$ & $\begin{array}{l}2.27(0.28,18.1) \\
0.00(0.00, \propto) \\
0.14(0.01,1.52) \\
0.19(0.02,1.79) \\
0.12(0.01,1.15) \\
0.39(0.04,3.53) \\
0.27(0.03,2.73) \\
0.22(0.02,2.19) \\
0.23(0.03,2.17)\end{array}$ \\
\hline
\end{tabular}


category in all except the lowest age group (0-4 years), where it is twice as high. Only nine $(2 \%)$ of the reported emergency appendicectomies occurred in this age group, however, and the rate ratio is not significantly different from unity in this or any other age group considered in isolation.

\section{Discussion}

The reported emergency appendicectomy rates in the cohort are higher than those found in data from the Oxford record linkage study, ${ }^{1}$ perhaps because many of the operations were performed at a time when acute appendicitis was more prevalent than it is today. However, the general pattern of values, with a peak during teenage years followed by a steady decline for both men and women, is similar in the two studies.

The association between meat eating and appendicectomy rates which we have found may, of course, be due to confounding factors. Participants were well matched for social class so this is unlikely to be a confounder. With regard to other dietary hypotheses, data from the diet and lifestyle questionnaire completed by all participants on entry to the study show that the non-meat eaters in the cohort generally have a higher intake of non-potato vegetables than the meat eaters. In the absence of information on the participants' vegetable consumption over time, however, it is impossible to test this particular hypothesis without making the crude (and undoubtedly incorrect) assumption that their vegetable intake at entry to the study is typical of their vegetable consumption throughout life. The same applies to other possible dietary hypotheses such as those suggesting a positive association between potato and sugar consumption and acute appendicitis. ${ }^{2}$ The available data suggest that the non-meat eaters in the cohort generally eat both potatoes and major sources of sugar in the diet less often than the meat eaters. Barker et al actually found a non-significant negative correlation between meat consumption and acute appendicitis, ${ }^{7}$ although the range of values observed (based on national food survey averages in 59 areas of England and Wales) may not have been sufficient to detect a real trend.

Similarly, it is not possible to test for an association with hygiene factors using our data, although if these are simply a reflection of socioeconomic status it should be noted that the social class distribution is similar for both meat eaters and non-meat eaters in the cohort.

Vegetarianism tends to be a part of a lifestyle which includes a general concern for health and health promoting behaviour, and changing to a vegetarian diet is likely to be related to other lifestyle changes which might affect health. Moreover, the diet of a vegetarian does not differ from that of non-vegetarians simply through the absence of meat. Thus, vegetarians are likely to have a higher consumption of vegetables, fruit, nuts, and other complex carbohydrates than non-vegetarians. For these reasons it will be difficult to determine what aspect of being a vegetarian might account for a reduced risk of appendicitis, if such a relationship were to be confirmed in other studies.

Retrospective data depending on participants' memory may be unreliable. However, we believe that such a substantial association between meat eating and reported emergency appendicectomy rates merits further investigation.

The Oxford vegetarian study was formerly supported by the Cancer Research Campaign and is currently supported by the Imperial Cancer Research Fund.

1 Primatesta P, Goldacre MJ. Appendicectomy for acute aprimatesta P, Goldacre MJ. Appendicectomy for acute appendicitis and for other conditions: An epidemiological study. Int f Epidemiol 1994;23:155-60.

2 Barker DJ, Morris J. Acute appendicitis, bathrooms, and diet in Britain and Ireland. $B M \mathcal{F} 1988 ; 296: 953-5$

3 Thorogood M, Mann J, Appleby P, McPherson K. Risk of death from cancer and ischaemic heart disease in meat and non-meat eaters. $B M \Im$ 1994;308:1667-71.

4 SPSS reference guide. SPSS Inc, Chicago, 1990.

5 Coleman MP, Hermon C, Douglas A. Person-years (PYRS): A Fortran program for cohort study analysis. Lyon: World A Fortran program for cohort study analysis. Lyon. World Cancer, 1989. Internal Report No 89/006.

6 Payne CD ed. The generalised linear interactive modelling system release 3.77 manual. Oxford: Numerical Algorithms Group, 1985

7 Barker DJ, Morris J, Nelson M. Vegetable consumption and acute appendicitis in 59 areas in England and Wales. BMF 1986;292:927-30. 